\title{
Bidirectional Halide Ion Exchange in Paired Lead Halide Perovskite Films with Thermal Activation
}

\author{
Elmelund, Tor; Scheidt, Rebecca A.; Seger, Brian; Kamat, Prashant V.
}

Published in:

ACS Energy Letters

Link to article, DOI:

10.1021/acsenergylett.9b01280

Publication date:

2019

Document Version

Peer reviewed version

Link back to DTU Orbit

Citation $(A P A)$ :

Elmelund, T., Scheidt, R. A., Seger, B., \& Kamat, P. V. (2019). Bidirectional Halide lon Exchange in Paired Lead Halide Perovskite Films with Thermal Activation. ACS Energy Letters, 4(8), 1961-1969.

https://doi.org/10.1021/acsenergylett.9b01280

\section{General rights}

Copyright and moral rights for the publications made accessible in the public portal are retained by the authors and/or other copyright owners and it is a condition of accessing publications that users recognise and abide by the legal requirements associated with these rights.

- Users may download and print one copy of any publication from the public portal for the purpose of private study or research.

- You may not further distribute the material or use it for any profit-making activity or commercial gain

- You may freely distribute the URL identifying the publication in the public portal 


\title{
Bidirectional Halide lon Exchange in Paired Lead Halide Perovskite Films with Thermal Activation
}

\author{
Tor Elmelund ${ }^{1,2}$, Rebecca A. Scheidt ${ }^{1}$, Brian Seger $^{2}$ and Prashant V. Kamat ${ }^{1 *}$ \\ ${ }^{1}$ Radiation Laboratory, Department of Chemistry \& Biochemistry, and \\ Department of Chemical \& Biomolecular Engineering \\ University of Notre Dame, Notre Dame, Indiana 46556, USA \\ and \\ ${ }^{2}$ SurfCat, Department of Physics \\ Technical University of Denmark \\ 2800 Kgs. Lyngby, Denmark
}

*Address correspondence to pkamat@nd.edu 
Abstract

$\mathrm{MAPbBr}_{3}$ and $\mathrm{MAPbl}_{3}$ films cast onto glass slides and physically paired together, undergo halide exchange to form mixed halide films. The change in halide composition in these two $\sim 130 \mathrm{~nm}$ thick films occurs concurrently with $\mathrm{Br}$ diffusing towards the $\mathrm{MAPbl}_{3}$ film and I diffusing towards the $\mathrm{MAPbBr}_{3}$ film. The diffusion of these halide species, which is tracked through changes in the absorption, offers a direct measurement of thermally activated halide diffusion in perovskite films. The increase in the rate constant of halide diffusion with increasing temperature (from $5 \times 10^{-5} \mathrm{~s}^{-1}$ at $23^{\circ} \mathrm{C}$ to $2.2 \times 10^{-3} \mathrm{~s}^{-1}$ at $140{ }^{\circ} \mathrm{C}$ ) follows an Arrhenius relationship with activation energy of $51 \mathrm{~kJ} / \mathrm{mole}$. The thermally activated halide exchange shows the challenges of employing layers of different metal halide perovskites in stable tandem solar cells.

\section{TOC Graphics}

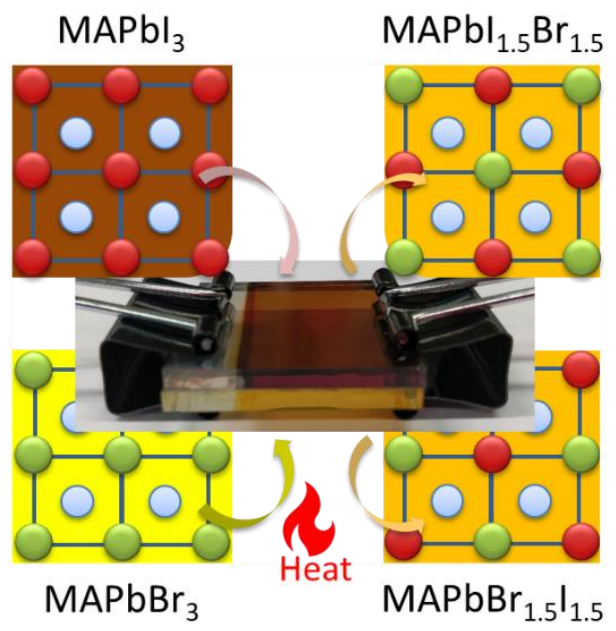


The interplay between ionic conductivity and electronic conductivity of metal halide perovskites has dominated the discussion of explaining their unusual optoelectronic and photovoltaic properties. ${ }^{1-6}$ In particular, halide ion mobility in metal halide perovskites plays an important role in determining the performance of perovskite solar cells. ${ }^{7-9}$ For example, the high ionic conductivity in $\mathrm{MAPbl}_{3}$ compared to the electronic conductivity along with high native ionic disorder leads to the trapping of the electronic carriers. ${ }^{10}$ The intrinsic ionic defects, specifically halide ion vacancies, often dictate the mobility of halide species within the perovskite film during the operation of solar cells. ${ }^{11,12}$ One such effect is the accumulation of halide ions near the electrode surface during the solar cell operation, thus increasing the cell capacitance. This effect often results in hysteresis between forward and reverse J-V (current-voltage) scans during solar cell operation. ${ }^{12-17}$ Thus, control of ion migration becomes important in decreasing such hysteresis effect. ${ }^{18}$ The built-in potential bias in the solar cell also induces drift velocity for the movement of halide ions which has been visualized through emission microscopy techniques. ${ }^{19-22}$ Impedance spectroscopy is another technique that is commonly used to elucidate the ionic conductivity both in dark and under illumination. Recently, Peng et al have correlated low-frequency response of $\mathrm{MAPbBr}_{3}$ single crystals with the chemical reactivity of moving ions towards hole transport layer interface to show the diffusion of halide ions through perovskite. ${ }^{23}$ The diffusion of halide ions towards the surface can either remediate the defects ${ }^{24,25}$ or can induce degradation of perovskite solar cells. ${ }^{26,27}$

One of the interesting aspects of halide mobility is the photoinduced phase segregation seen in mixed halide perovskite films under steady state irradiation ${ }^{11,28-32}$ and its effect on solar cell performance. ${ }^{33-35}$ The halide ion segregation in these films has been tracked through absorption and emission spectroscopy. ${ }^{29,31,36}$ Upon storage in dark, the process is reversed and the original mixed halide composition is restored. Several explanations have been provided to gain insight into the photoinduced movement of halide ions. These explanations include polaron induced strain, ${ }^{37}$ two state model in the excited state $^{38}$ and halide ion defect driven movement. ${ }^{31,39}$ While the debate continues to explain photoinduced halide ion segregation, a similar one on why they reverse movement in dark to regenerate mixed halide composition is ongoing.

The recent results on halide ion exchange between semiconductor nanocrystals to form mixed halide perovskite nanocrystals or nanostructured films show that site sharing between halides is favored by perovskite nanocrystals. ${ }^{40-42}$ For example, Akkerman et al have shown previously that the exchange of halide ions between $\mathrm{CsPbBr}_{3}$ and $\mathrm{CsPb}_{3}$ readily proceeds when two nanocrystals are mixed in solution. ${ }^{40}$ The mixed phase appears to be thermodynamically favored phase when these two separately synthesized 
nanocrystals are stored together in the dark. In order to establish thermally activated halide movement of halide ions in metal halide perovskite films we have spectroscopically probed the evolution of mixed halide composition at different temperatures. The mechanistic and kinetic details of bromide and iodide movement between physically paired films are discussed.

Homogenization of Paired Perovskite Films. Films of $\mathrm{MAPbBr}_{3}$ and $\mathrm{MAPbl}_{3}$ (see Supporting information for experimental procedure) were cast onto separate FTO (fluorine doped tin oxide) coated glass slides in a glove box and annealed at $100{ }^{\circ} \mathrm{C}$ for 10 minutes for $\mathrm{MAPbBr}_{3}$ while $\mathrm{MAPbl}_{3}$ films were annealed for

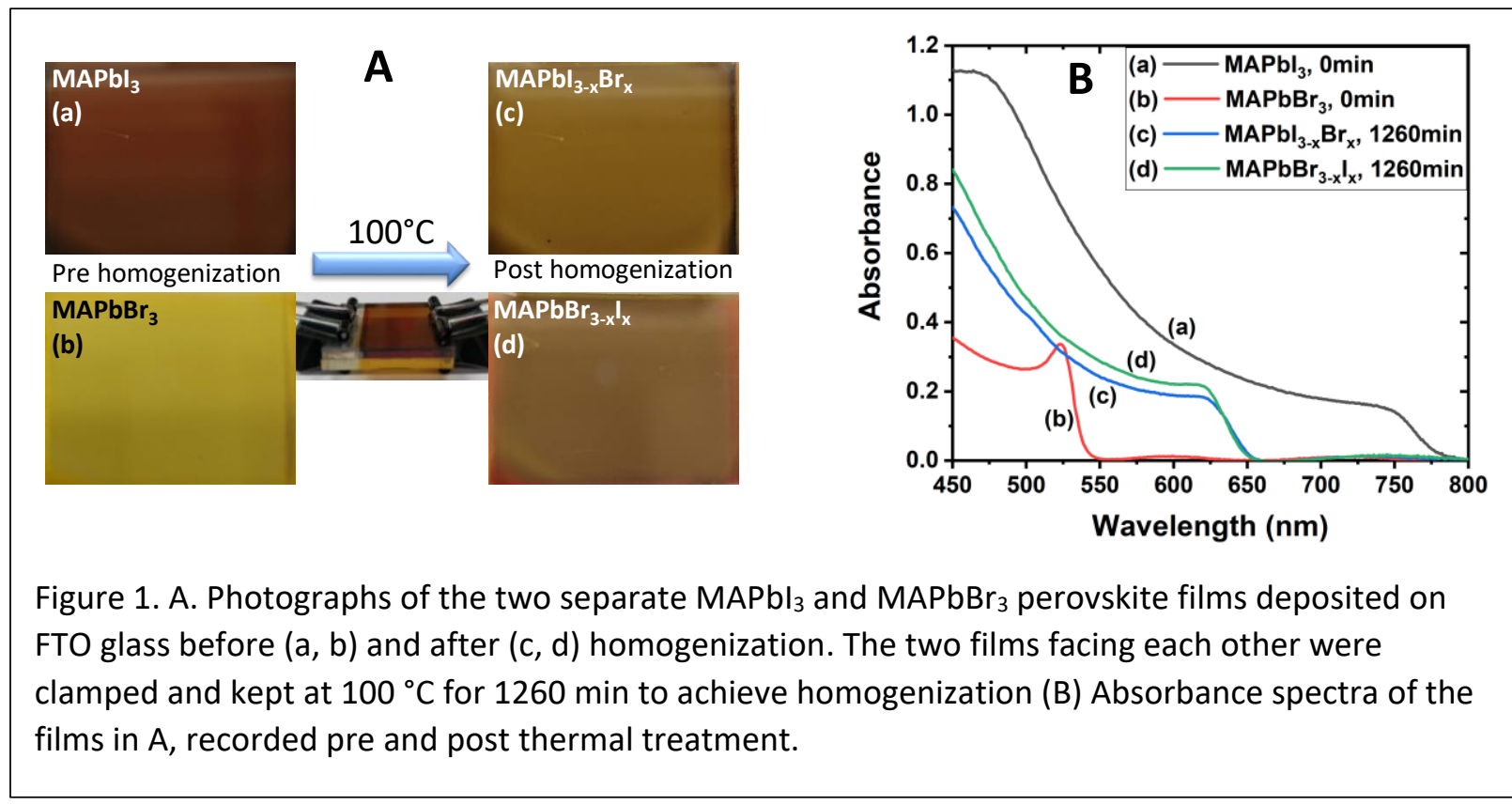

1 minute at $65^{\circ} \mathrm{C}$ followed by immediate annealing at $100{ }^{\circ} \mathrm{C}$ for 2 minutes. The annealed films were paired together such that the films are physically in contact with each other. The slides were clamped with binder clips and placed on a temperature-controlled hot plate. Care was taken to maintain the temperature around the glass slide assembly at constant temperature. The clamped slides were periodically transferred to a Carry-50 UV-visible spectrophotometer to record the absorption spectra at different times and monitor changes in the absorbance associated with variations in the halide composition leading to homogenization of the films.

Figure $1 \mathrm{~A}$ shows the individual slides coated with $\mathrm{MAPbBr}_{3}$ and $\mathrm{MAPbl}_{3}$ films before (pre-homogenization) and after (post-homogenization) heat treatment at $100{ }^{\circ} \mathrm{C}$ for $1260 \mathrm{~min}$ ( 21 hours). The corresponding absorption spectra of these two films are shown in Figure 1B. As prepared films of $\mathrm{MAPbBr}_{3}$ and $\mathrm{MAPbl}_{3}$ are visibly and spectrally different exhibiting excitonic absorption at $523 \mathrm{~nm}$ and $750 \mathrm{~nm}$ respectively. Both films exhibit matching absorption onsets following homogenization at $100{ }^{\circ} \mathrm{C}$ indicating the same 

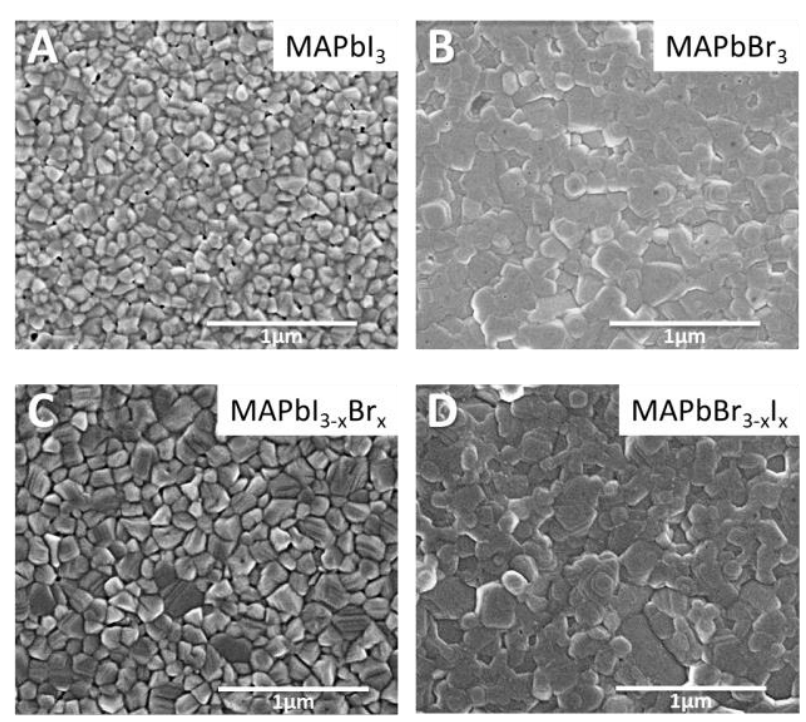

Figure 2. Top down SEM images of as prepared $(A)$ $\mathrm{MAPbl}_{3}$ and (B) $\mathrm{MAPbBr}_{3}$ films (pre (0 min) homogenization) (C) and (D) same films following homogenization at $100^{\circ} \mathrm{C}(1260 \mathrm{~min})$. All images were acquired at $100000 \mathrm{X}$ magnification. optical band gap, which is supported by visual inspection of the separated films color (Figure 1A). These results show that upon subjecting these two paired films to a temperature of 100 ${ }^{\circ} \mathrm{C}$ they undergo homogenization as the $\mathrm{Br}$ and I migrate from one film into the other, viz: $\mathrm{Br}$ moving towards $\mathrm{MAPbl}_{3}$ film side and I moving towards $\mathrm{MAPbBr}_{3}$ side until complete homogenization occurs and a mixed halide perovskite is formed.

Figure 2 shows the SEM images of the two films employed in the illustration of Figure 1A. The overall morphology of the two films remains unaffected following the halide exchange between the two films at $100^{\circ} \mathrm{C}$ after $1260 \mathrm{~min}$.

(The SEM images of intermediate samples recorded after $600 \mathrm{~min}$ and $900 \mathrm{~min}$ are shown in Figure S1 and cross-sectional SEM images are shown in Figure S2.) However, a slight increase in grain size seen in Figures $2 \mathrm{C}$ and $\mathrm{D}$ is likely to arise from to the effect of extended thermal annealing during homogenization step. The average $\mathrm{MAPbl}_{3}$ grain size increases from 120 to $155 \mathrm{~nm}$ following homogenization at $100{ }^{\circ} \mathrm{C}$ (Figure S3) as seen in previous studies into perovskite grain growth under annealing. ${ }^{43}$ Based on these images it is possible to conclude that there is no major change in morphology following the halide exchange process.

In another experiment, we employed two different mixed halide films with dissimilar Br:I ratios (viz.,

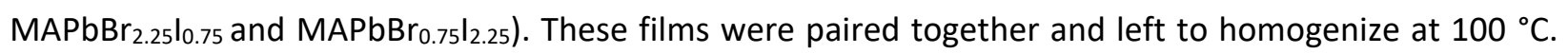
The absorption spectra recorded before and after $1260 \mathrm{~min}$ of homogenization period are shown in Figure S4 (supporting information). Despite the initial $\mathrm{Br}$ :I ratio both films attained similar 1:1 mixed halide composition as confirmed by the absorption spectra and also by XPS analysis. These results further confirm the ability of halides to mobilize to attain a stable mixed halide composition. 
The absorption spectra in Figure $3 \mathrm{~A}$ show the collective absorption changes of the paired $\mathrm{MAPbl}_{3}$ and $\mathrm{MAPbBr}_{3}$ films at intermediate time points of annealing $\left(100^{\circ} \mathrm{C}\right)$. The changes in absorption was probed by rapidly transferring the clamped slides to the spectrophotometer at different time points, acquiring a spectrum, and returning the clamped system to the hotplate. The constant temperature maintained
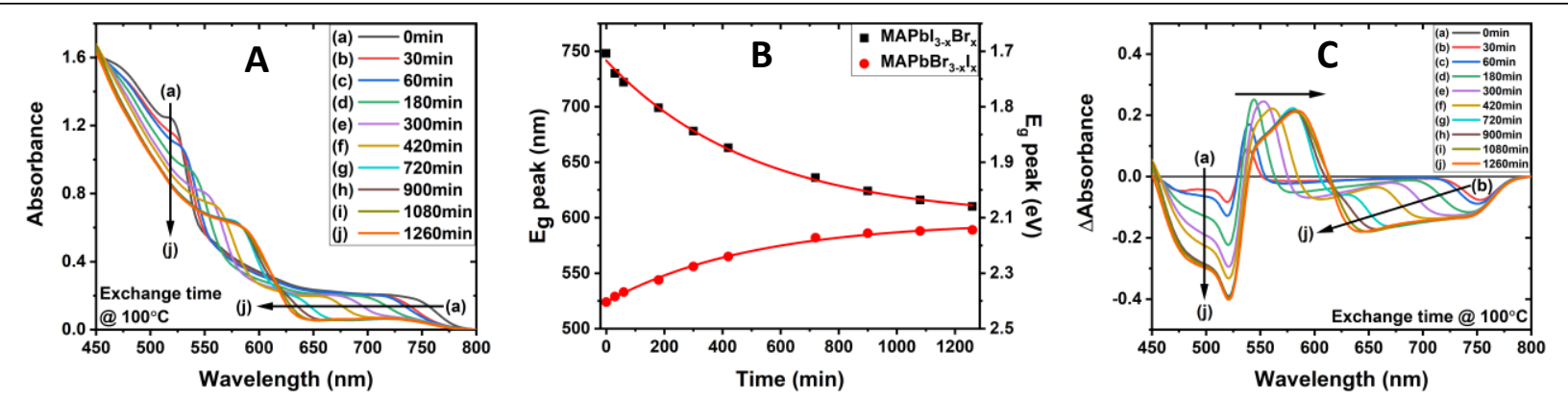

Figure 3. (A) Absorption spectra of paired $\mathrm{MAPbl}_{3} / \mathrm{MAPbBr}_{3}$ perovskite films recorded at different times of homogenization $\left(100^{\circ} \mathrm{C}\right)$. (B) Gradual change in absorbance of paired films during homogenization process is tracked through the shift in excitonic peak in terms of wavelength and energy. The kinetic traces have been fitted with a monoexponential fit to guide the eye. (C) Difference absorbance spectra obtained from spectra $b-j$ in $(A)$ with 0 minute spectrum $(a)$ being used as a reference.

during the homogenization process allowed exchange of $\mathrm{Br}$ and I to proceed between the two films continuously. The changes in the $\mathrm{Br} / \mathrm{l}$ composition during the homogenization process is seen from the red-shift of the $\mathrm{MAPbBr}_{3}$ excitonic peak $\left(523 \mathrm{~nm}\right.$ ) and simultaneous blue-shift of the $\mathrm{MAPbl}_{3}$ band edge $(750 \mathrm{~nm})$ with increasing time. At the end of homogenization period (1260 min) the two absorption peaks merge exhibiting a maximum at $589 \mathrm{~nm}$. This excitonic peak, which lies between the absorption edge of the original $\mathrm{MAPbBr}_{3}$ and $\mathrm{MAPbl}_{3}$ films corresponds to the absorption of a mixed halide film confirming the homogenization of both perovskite films. The position of the peak at $589 \mathrm{~nm}$ is also indicative of 1:1 distribution of $\mathrm{Br}$ and $\mathrm{I}$ in the homogenized film. The peak shift seen in these absorption spectra during the initial period are plotted in Figure 3B. At the end of the homogenization process these peaks become indistinguishable thus confirming the two films to contain identical $\mathrm{Br}: \mathrm{I}$ ratio.

The difference spectra recorded in Figure $3 \mathrm{C}$ further highlights the changes in the absorbance of the films during annealing. The dominant $\mathrm{MAPbBr}_{3}$ peak at $523 \mathrm{~nm}$ shows continuous decrease in its absorption with time. During the same period the loss of iodide absorption is represented by the change in the band edge with a blue shift in the peak. Once no further shift in the absorbance spectra is seen, and when the two films were taken apart and measured separately, the band positions were the same (Figure 1B). With the exchange of $\mathrm{Br}$ and I between the films the increased absorption at $580 \mathrm{~nm}$ becomes a dominant 
feature of the paired film. The experimental results presented in Figures 1 and 3 show that the halide ions are mobile and cross the physical barrier when the two films are kept in contact with each other. The
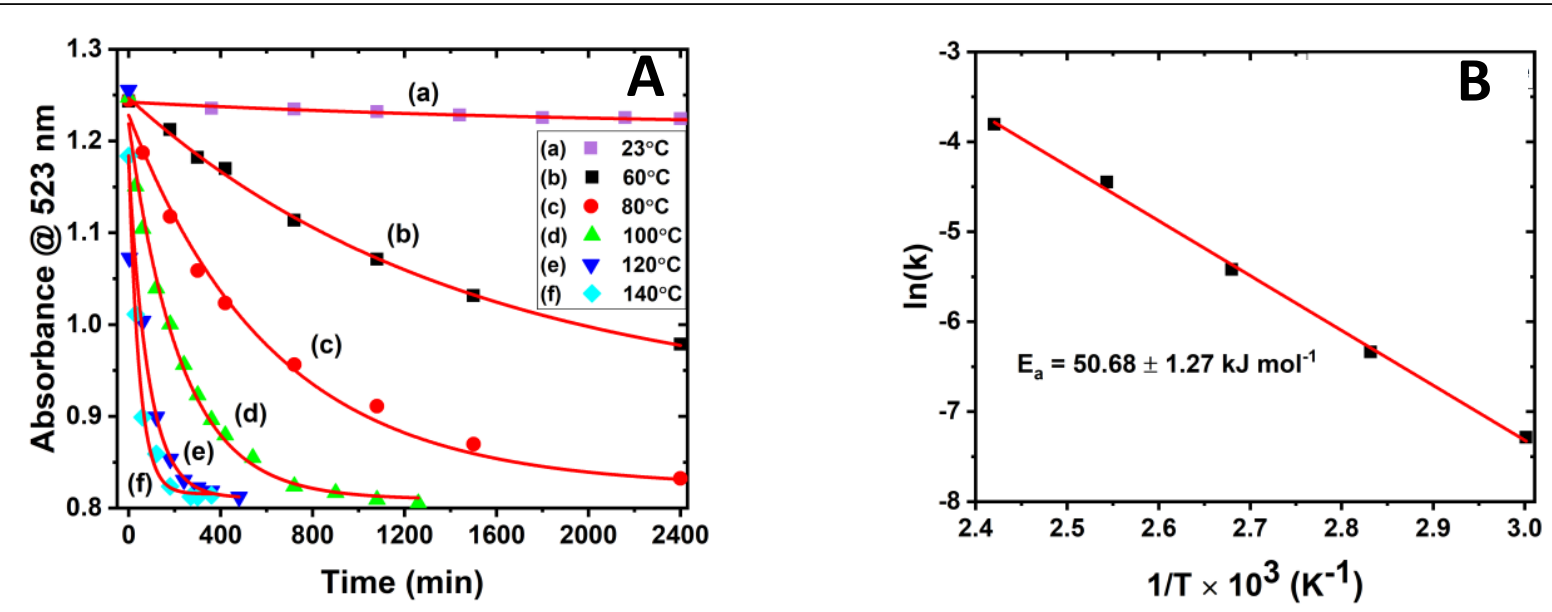

Figure 4. (A) Change in absorbance of $\mathrm{MAPbBr}_{3}$ excitonic peak $(523 \mathrm{~nm}$ ) with time during the homogenization process (a) $23^{\circ} \mathrm{C}$, (b) $60^{\circ} \mathrm{C}$, (c) $80^{\circ} \mathrm{C}$, (d) $100{ }^{\circ} \mathrm{C}$, (e) $120^{\circ} \mathrm{C}$, and (f) $140{ }^{\circ} \mathrm{C}$. The traces were fitted with a monoexponential fit to determine pseudo first rate constants of halide ion mobility. (B) Arrhenius plot of natural log of the rate constants versus the inverse of temperature.

ability to undergo complete $\mathrm{Br} / \mathrm{l}$ exchange between the two physically paired film highlights that the most favored phase consists of mixed halide composition.

Thermally Activation of Halide Ion Mobility. Thus far, we have discussed films at annealed $100^{\circ} \mathrm{C}$. If the exchange of $\mathrm{Br} / \mathrm{l}$ is induced by thermal activation, we should be able to see a strong dependence on temperature for the rate of diffusion. The experiment described in Figure 3 was therefore repeated by maintaining different temperatures for homogenization. The halide ion exchange rates as measured from the changes in the absorption of $\mathrm{MAPbBr}_{3}$ excitonic peak at $523 \mathrm{~nm}$ with time at different temperatures are shown in Figure 4. The individual absorption spectra corresponding to these experiments are included in Figure S5. The halide ion exchange rate was negligibly slow at room temperature but becomes more prominent as the paired films are subjected to elevated temperature. At temperatures greater than 100 ${ }^{\circ} \mathrm{C}$ the homogenization was completed within $\sim 10$ hours. All traces in Figure 4A were fitted to monoexponential decay to determine the pseudo first order rate constants of halide ion mobility. The apparent rate constant for halide ion movement increased from $1.14 \times 10^{-5} \mathrm{~min}^{-1}$ to $3.70 \times 10^{-4} \mathrm{~min}^{-1}$ as the temperature was increased from $60{ }^{\circ} \mathrm{C}$ to $140{ }^{\circ} \mathrm{C}$. This dependence of halide ion mobility on temperature was further analyzed through the Arrhenius expression (1)

$$
\ln (k)=-E_{a} / R T+\ln (A)
$$


The straight line fitted to the plot of $\ln (k)$ versus $1 / T$ (Figure $4 B$ ) confirms the validity of Arrhenius relationship with activation energy of $50.7 \mathrm{~kJ} / \mathrm{mole}$ for the movement of halide ions. This value is comparable to activation energy of $0.62 \mathrm{eV}$ (or $59 \mathrm{~kJ} / \mathrm{mole}$ ) estimated from the photocurrent measurements. ${ }^{44}$ While previous studies ${ }^{36,45}$ estimate the diffusion of iodide (or iodide vacancies) under light irradiation, the present study exclusively estimates the halide diffusion under thermal activation in the film. Although the diffusion of halide ions in perovskite films is extremely slow, it becomes faster at elevated temperature. At $60^{\circ} \mathrm{C}$ the halide ion diffusion coefficient is estimated to be around $1.13 \times 10^{-13}$ $\mathrm{cm}^{2} / \mathrm{s}$ which increases with an order of magnitude at $120^{\circ} \mathrm{C}$ (Table 1 ). Mobility of halide ion vacancies $\left(10 \mu \mathrm{m} \mathrm{s}^{-1}\right)$ have also been measured for $\mathrm{MAPbl}_{3}$ films under electrical bias with iodide diffusion coefficient of $2.4 \times 10^{-8} \mathrm{~cm}^{2} / \mathrm{s} .{ }^{46}$ The difference in values obtained in our study arises from lack of external driving force (e.g. lack of uniform contact between two films) other than thermal activation.

Using a simplified version of Fick's second law for diffusion, an effective diffusion coefficient is calculated. The argument for using a simplified version and the term effective diffusion coefficient is that for this process, two different sized ions $\left(\mathrm{I}^{-}\right.$and $\left.\mathrm{Br}^{-}\right)$diffuse in opposite directions with different rates hence making the law of diffusion analytically unsolvable. The effective diffusion coefficients as measured from the expression (2) are listed in Table 1.

$$
D_{\text {eff }}=L^{2} / \tau_{\text {diff }}
$$

$D_{\text {eff }}$ is the effective diffusion coefficient, $\tau_{\text {diff }}$ is the lifetime measured from the plots in Figure $4 \mathrm{~A}$ and $L$ is the diffusion length or the average film thickness $(128.5 \mathrm{~nm})$. The diffusion length is set to the distance between the center of the two films, which is made under the assumption that there is only diffusion in one direction between the films and no lateral ion movement with the film.

Table 1

Halide Ion Diffusion Parameters

\begin{tabular}{|c|r|c|}
\hline Temperature $\left(^{\circ} \mathbf{C}\right)$ & Lifetime, $\tau(\mathbf{s})$ & Diffusion Coefficient, $\mathbf{D}\left(\mathbf{c m}^{2} \mathbf{~ s}^{-1}\right)$ \\
\hline 23 & $\sim 2000$ & $\sim 8.26 \times 10^{-14}$ \\
\hline 60 & 1460.0 & $1.13 \times 10^{-13}$ \\
\hline 80 & 566.0 & $2.92 \times 10^{-13}$ \\
\hline 100 & 226.2 & $7.30 \times 10^{-13}$ \\
\hline
\end{tabular}




\begin{tabular}{|l|r|c|}
\hline 120 & 85.6 & $1.93 \times 10^{-12}$ \\
\hline 140 & 45.0 & $8.26 \times 10^{-12}$ \\
\hline
\end{tabular}

The observed values are consistent with the reported values from theoretical modeling. For example, Walsh and Stranks estimated a diffusion coefficient of $10^{-12} \mathrm{~cm}^{2} \mathrm{~s}^{-1}$ for $\mathrm{I}^{-}$ions at a temperature of $50{ }^{\circ} \mathrm{C} .{ }^{47}$ However, a greater halide ion diffusion coefficient $\left(1.76 \times 10^{-8} \mathrm{~cm}^{2} \mathrm{~s}^{-1}\right)$ was estimated for $\mathrm{MAPbBr}_{3}$ single crystals using impedance spectroscopy. ${ }^{23}$ It should be noted that the halide ion migration in the present study is a bulk diffusion of two physically separated films leading to the complete homogenization. Hence the conditions for halide ion diffusion differs from those in single crystals or halide vacancy driven migration under photoirradiation. Additionally, the measurements presented in the present study deal with the movement of halide ions of different ionic radii, which also contributes to the overall mobility of the halide ions through the crystal structure. 
XPS Analysis. To further study the movement of halide ions across the interface of the $\mathrm{MAPbl}_{3}$ and the
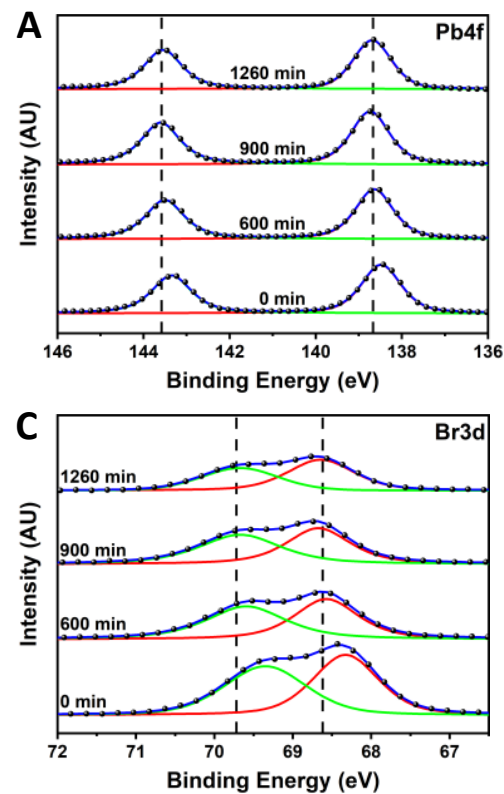
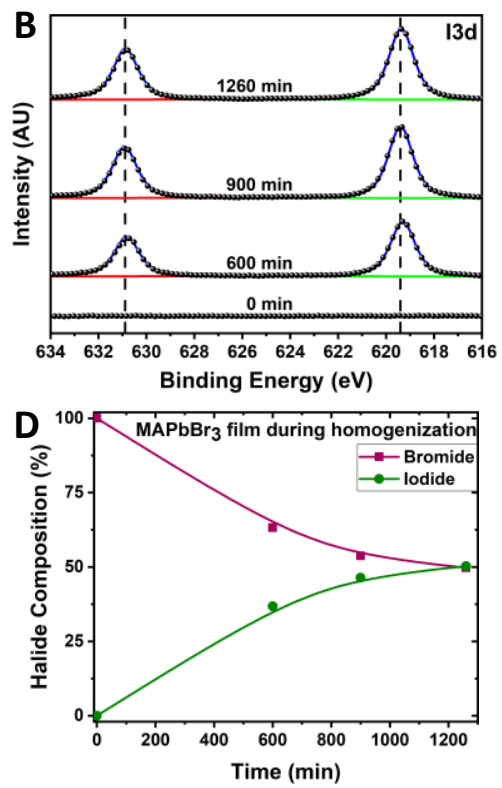

$\mathrm{MAPbBr}_{3}$ films during the homogenization process, XPS analysis was carried out in order to determine the concentration of bromide and iodide ions on the surface of the films.

XPS spectra were recorded at $0,600,900$, and 1260 minutes following the thermal treatment of paired films at $100{ }^{\circ} \mathrm{C}$. Figures $5 \mathrm{~A}-5 \mathrm{C}$ show representative XPS of selected elemental regions for the $\mathrm{MAPbBr}_{3}$ film throughout the thermal treatment process. At 0 minutes (before subjecting to thermal treatment), no iodide peaks can be resolved due to the absence of iodide in the films. However, by 600 minutes of annealing, iodide is clearly present in the film. Similar trend of increasing concentration of $\mathrm{Br}$ with increasing time of heating was observed in the opposite fashion for the $\mathrm{MAPbl}_{3}$ film (Figure S6).

Using pseudo-Voigt fitting parameters, the ratio of halide ion composition of the $\mathrm{MAPbBr}_{3}$ film was found throughout the annealing process. Figure 5D shows that the halide composition shifts from $100 \%$ bromide at 0 minutes of annealing to $50 \%$ bromide at the end of the homogenization process. This supports the spectral data in Figure 3 which shows that a mixed halide perovskite with a chemical formula of $\mathrm{MAPbBr} \mathrm{P}_{1.5} \mathrm{I}_{1.5}$ was obtained. For every time point 3-4 areas on each of the slides were analyzed showing less than $1 \%$ deviation in the halide ion composition ratio. The same trend was seen in the $\mathrm{MAPbl}_{3}$ film in Figure S6D showing that all halide ions are accounted for and do not preferentially migrate to one side of the films. It should be mentioned that the use of XPS is only a surface technique, as it was not possible 
to perform depth analysis using XPS due to degradation of the perovskite films. Hence, the measured 1:1 ratio of $\mathrm{I}: \mathrm{Br}$ is only at the interface $(<5 \mathrm{~nm})$.

We also probed the chemical changes at the surface of both films during the thermal treatment process. The binding energy of the various species were analyzed to determine changes that might have occurred at the surface of perovskite films during the homogenization process. Between 0 minutes and 600 minutes of homogenization step, the binding energy of both the bromide and lead peaks shift to higher binding energy. This shift indicates that these species are slightly oxidized and therefore more strongly bound through coulombic interactions than they are at the prehomogenization process. We attribute this shift to oxidized states formed as a result of exposure to air at elevated temperatures ${ }^{48}$ similar to the effect seen on $\mathrm{MAPbl}_{3}$ films under irradiation. ${ }^{49}$ All of the binding energies, both before and throughout the annealing process, show a high fidelity to previously reported binding energies for MAPbX films $^{50}$ It should be noted that the surface changes probed through XPS is a minor pathway and does not influence the overall halide exchange process in the bulk. 

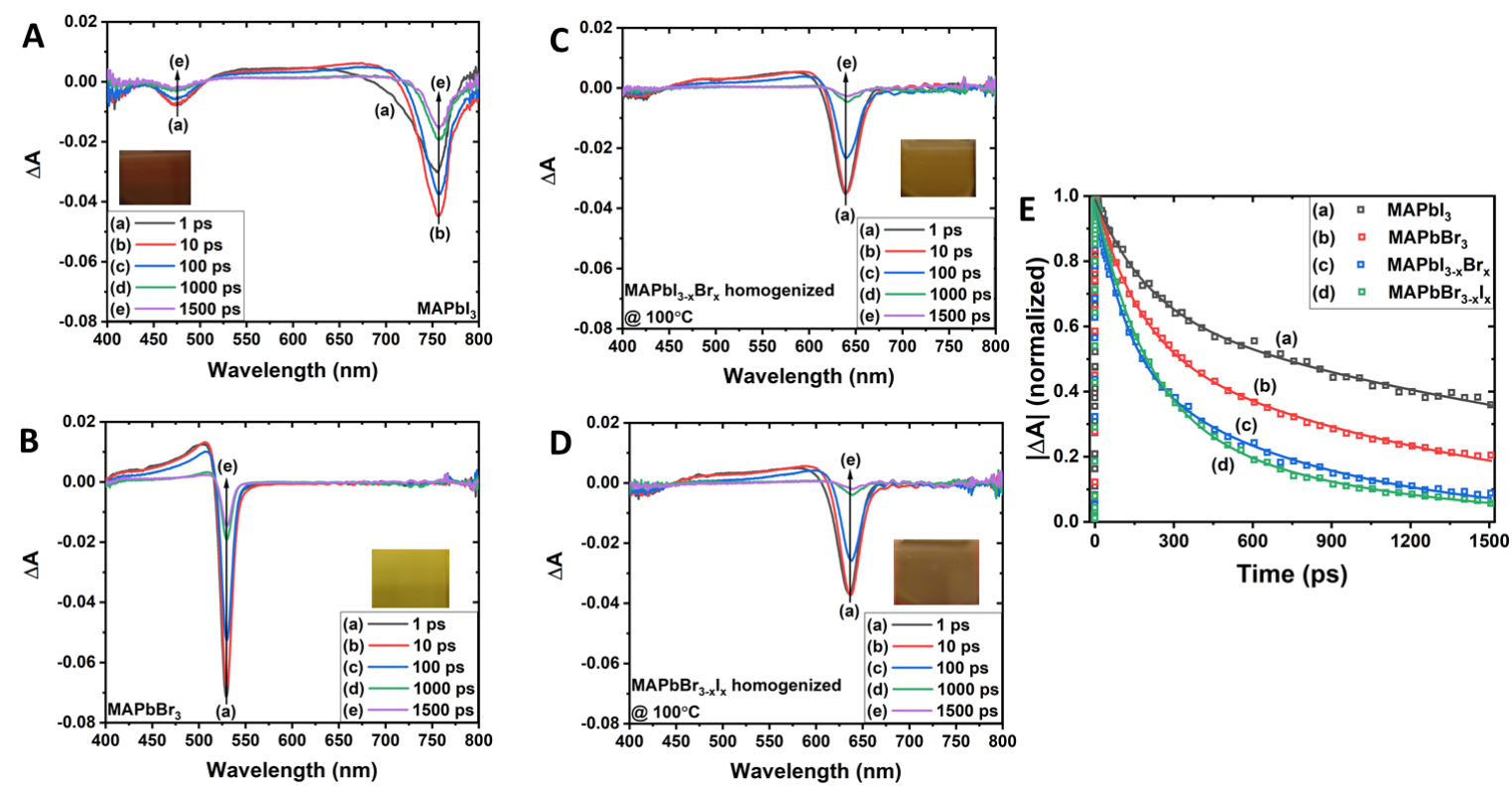

Figure 6. Time-resolved transient absorption (TA) spectra recorded following laser pulse excitation with $387 \mathrm{~nm}$ of $\mathrm{MAPbl}_{3}$ and $\mathrm{MAPbBr}_{3}$ films (A, B) before and $(\mathrm{C}, \mathrm{D})$ after homogenization. $(\mathrm{E})$ Recovery of bleaching of four films recorded at bleach maxima: (a) $\mathrm{MAPbl}_{3}\left(757 \mathrm{~nm}\right.$ ), (b) $\mathrm{MAPbBr}_{3}$ $(529 \mathrm{~nm})$ and (c) \& (d) homogenized films $(637 \mathrm{~nm})$. Insets in (A) to (D) panels are the photographs the films employed in the respective TA measurements.

Excited State Dynamics of Pre- and Post-Homogenized Films. We also employed femtosecond transient absorption spectroscopy to probe the completion of halide ion exchange and its influence on excited state dynamics. Each of the paired films ( $\mathrm{MAPbBr}_{3}$ and $\mathrm{MAPbl}_{3}$ ) were subjected to $387 \mathrm{~nm}$ laser pulse excitation before and after the completion of the homogenization step. These films correspond to those discussed in Figure 1. The time resolved transient absorption spectra and corresponding bleaching recovery are presented in Figure 6. As prepared films of $\mathrm{MAPbBr}_{3}$ and $\mathrm{MAPbl}_{3}$ exhibit characteristic bleach at wavelengths of $529 \mathrm{~nm}$ and $757 \mathrm{~nm}$ respectively following the excitation with $150 \mathrm{fs}$ laser pulse (387 nm). The bleach recovery is seen over the period of nanoseconds as photogenerated charge carriers recombine. A detailed discussion of bimolecular and trap assisted charge carrier recombination in pristine lead halide films can be found in earlier published work. ${ }^{51-55}$ Prior to homogenization the individual films exhibit bleach maxima at $757 \mathrm{~nm}$ and $529 \mathrm{~nm}$ for $\mathrm{MAPbl}_{3}$ (Figure 6A) and $\mathrm{MAPbBr}_{3}$ (Figure 6B), respectively. The interesting aspect is when these two films are brought in contact with each other and allowed to homogenize at $100{ }^{\circ} \mathrm{C}$. The transient absorption spectra of the homogenized films now exhibit similar bleach maximum at $637 \mathrm{~nm}$ thus confirming the matching composition of the mixed halide film (Figures $6 \mathrm{C}$ and D). These transient absorption measurements confirm that the perovskite films do not 
retain the individual excited state characteristics of the original films, but with those of mixed halide perovskites. ${ }^{56}$

We also investigated the charge carrier recombination of the pre- and post- homogenized films (Figure $6 \mathrm{E})$. The bleach signal of the now mixed halide perovskite films recovers with a rate faster than those of original perovskite films. The average lifetimes of bleaching recovery ( 844 ps for $\mathrm{MAPbBr}_{3}$ and 1722 ps for $\mathrm{MAPb}_{3}$ ) decreased to about $457 \mathrm{ps}$ for the homogenized mixed halide films. The fitting parameters are shown in Table S1. The marked change in the excited state decay of the film before and after annealing can be attributed to the heterogeneity of the halide ions in mixed-ion lead perovskite thin films which have been shown to affect local charge carrier dynamics. ${ }^{57}$ The decreased excited state lifetime also suggests that the halide exchange process has created more surface defects at the grain boundaries leading to enhanced rate of charge recombination. Such additional movement of halide ions under photoirradiation can also be beneficially used to remediate surface defects and overcome some of the adverse effects. ${ }^{26}$

On the Mobility of Halide Ions. Halide ion exchange has been extensively used to obtain the desired composition of mixed halide films of different bandgaps by exposing a lead halide film (e.g., $\mathrm{MAPbBr}_{3}$ ) to another halide ions (e.g., iodide) solution. ${ }^{41,42}$ This exchange of halide ions is fully reversible and the original film can be restored by treating the mixed halide film with original halide ions in solution. Similarly, exchange of $\mathrm{Br}$ and I can also be achieved by mixing $\mathrm{CsPbBr}_{3}$ and $\mathrm{CsPb}_{3}$ nanocrystals suspended in solution. ${ }^{40,58}$ The simplicity of halide ion exchange process can be utilized to design a halide gradient structure within the $\mathrm{CsPbBr}_{3}$ film by controlling the exposure time to halide solution. ${ }^{59}$ The ease of halide ion diffusion and exchange between these two lead halide perovskite films shows inherent softness of the perovskite crystal structure. The results discussed in the present study offer a unique way to investigate the halide ion diffusion between two physically paired films of $\mathrm{MAPbBr}_{3}$ and $\mathrm{MAPbl}_{3}$.

There have been several theoretical and spectroscopic studies to explain the halide ion movement within the perovskite films. ${ }^{7,12,29,30,39,60,61}$ The defects or halide ion vacancies are thought to be crucial in driving the halide ion movement within the perovskite film. While such defect driven halide ion movement plays an important role during photoirradiation (as in the case of solar cell operation), the thermally activated diffusion shows the thermodynamic preference to attain a mixed composition of halides in perovskite films (Scheme 1). 


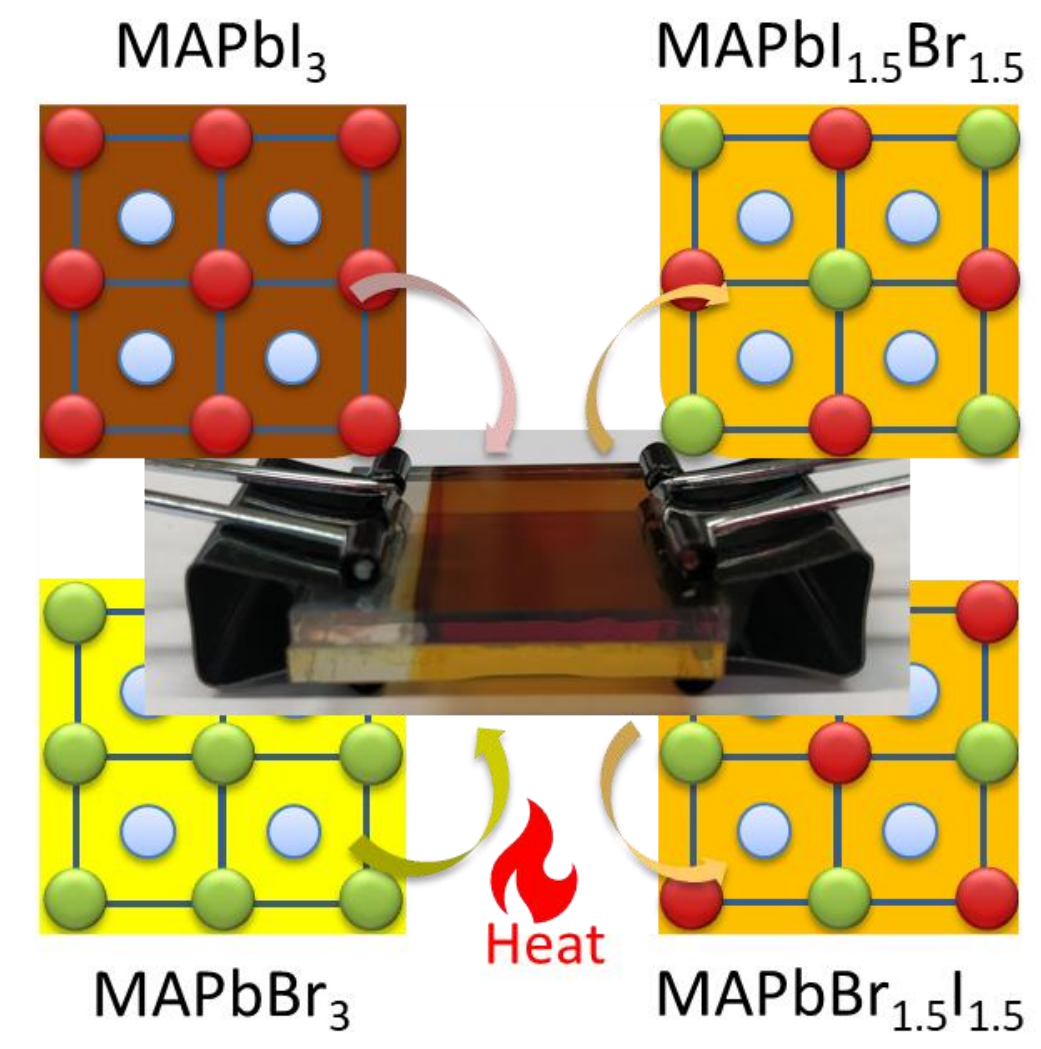

Scheme 1. Thermal activation of halide diffusion to produce homogenized perovskite films

The thermally activated halide ion diffusion presented in the present study contrasts the movement of halide ions under light activation. Under photoirradiation the mixed halide films undergo halide segregation to produce $\mathrm{Br}$-rich and I-rich domains. These domains remain segregated as long as light continues to shine the film. The light activation enables halide ions to overcome the thermodynamic barrier of entropy of halide ion mixing in perovskite films. ${ }^{62}$ Once the light is turned off the perovskite films return to original mixed halide favored configuration. The results presented here offer an explanation to why the films prefer to attain a mixed halide composition when the photoirradiated films are stored in the dark. This process occurs due to entropy of mixing favoring a homogenized configuration for metal halide perovskites at room temperature. Efforts are therefore needed to minimize the interlayer diffusion by including a chemical barrier (e.g., $\left.\mathrm{PbSO}_{4}\right)^{63}$ or employ long-chain organic ammonium capping layers ${ }^{64}$ between layered films of different halide composition. Additionally, as shown in this study the mobility of halide ions in perovskite films is strongly dependent on the temperature and gets accelerated 
at higher temperature. Since the outdoor operation of solar cell involves both light and heat, the halide ion mobility becomes an important issue. Thus, there is a need to obtain greater insights into the combined effect of irradiation, which causes halide segregation, and heat, which causes halide ion mixing, in mixed halide perovskite films. Efforts are underway to investigate these effects as well as their influence on the perovskite solar cell operation.

Acknowledgment: P.V.K., RAS and TE acknowledges the support of the Division of Chemical Sciences, Geosciences, and Biosciences, Office of Basic Energy Sciences of the U.S. Department of Energy, through award DE-FC0204ER15533. B.S. would like to thank funding from the Villum Foundation V-SUSTAIN Grant 9455. TE and BS would also like to acknowledge the support from Technical University of Denmark, with the fellowship for conducting collaborative research at Notre Dame. R.A.S. acknowledges the support of the Arthur J. Schmitt Leadership Fellowship This is contribution number NDRL No. 5244 from the Notre Dame Radiation Laboratory. The authors would also like to thank Prof. M. K. Kuno for helpful discussions as well as Dr. Tatyana Orlova of the Notre Dame Integrated Imaging Facility for her helpful discussion on cross-sectional SEM.

Supporting Information: The supporting information contains synthetic and annealing procedures, and experimental procedures (UV-Vis absorbance, Transient absorption, TEM, and XPS) and the detailed results on the absorption and XPS measurements.

\section{References.}

1. Eames, C.; Frost, J. M.; Barnes, P. R. F.; O'Regan, B. C.; Walsh, A.; Islam, M. S. Ionic transport in hybrid lead iodide perovskite solar cells, Nature Communications 2015, 6, Article No. 7497.

2. Johnston, M. B.; Herz, L. M. Hybrid Perovskites for Photovoltaics: Charge-Carrier Recombination, Diffusion, and Radiative Efficiencies, Accounts of Chemical Research 2016, 49, 146-154.

3. Manser, J. S.; Christians, J. A.; Kamat, P. V. Intriguing Optoelectronic Properties of Metal Halide Perovskites, Chemical Reviews 2016, 116, 12956-13008.

4. Wang, H.; Bou, A.; Guerrero, A.; AlMayouf, A. M.; Bisquert, J. Kinetic and Material Properties of Interfaces Governing Slow Response and Long Timescale Phenomena in Perovskite Solar Cells, Energy \& Environmental Science 2019, DOI: 10.1039/c9ee00802k.

5. Schulz, P.; Cahen, D.; Kahn, A. Halide Perovskites: Is It All about the Interfaces?, Chemical Reviews 2019, 119, 3349-3417.

6. Rosales, B. A.; Hanrahan, M. P.; Boote, B. W.; Rossini, A. J.; Smith, E. A.; Vela, J. Lead Halide Perovskites: Challenges and Opportunities in Advanced Synthesis and Spectroscopy, ACS Energy Letters 2017, 2, 906-914.

7. Yuan, Y.; Huang, J. Ion Migration in Organometal Trihalide Perovskite and Its Impact on Photovoltaic Efficiency and Stability, Accounts of Chemical Research 2016, 49, 286-293. 
8. Li, C.; Tscheuschner, S.; Paulus, F.; Hopkinson, P. E.; Kiessling, J.; Kohler, A.; Vaynzof, Y.; Huettner, S. Iodine Migration and its Effect on Hysteresis in Perovskite Solar Cells, Advanced Materials 2016, 28, 2446-2454.

9. Senocrate, A.; Moudrakovski, I.; Kim, G. Y.; Yang, T.-Y.; Gregori, G.; Grätzel, M.; Maier, J. The Nature of Ion Conduction in Methylammonium Lead lodide: A Multimethod Approach, Angewandte Chemie International Edition 2017, 56, 7755-7759.

10. Yang, T.-Y.; Gregori, G.; Pellet, N.; Grätzel, M.; Maier, J. The Significance of Ion Conduction in a Hybrid Organic-Inorganic Lead-lodide-Based Perovskite Photosensitizer, Angewandte Chemie International Edition 2015, 54, 7905-7910.

11. Gratia, P.; Grancini, G.; Audinot, J.-N.; Jeanbourquin, X.; Mosconi, E.; Zimmermann, I.; Dowsett, D.; Lee, Y.; Grätzel, M.; De Angelis, F.; Sivula, K.; Wirtz, T.; Nazeeruddin, M. K. Intrinsic Halide Segregation at Nanometer Scale Determines the High Efficiency of Mixed Cation/Mixed Halide Perovskite Solar Cells, Journal of the American Chemical Society 2016, 138, 15821-15824.

12. Lee, H.; Gaiaschi, S.; Chapon, P.; Marronnier, A.; Lee, H.; Vanel, J.-C.; Tondelier, D.; Bourée, J.-E.; Bonnassieux, Y.; Geffroy, B. Direct Experimental Evidence of Halide Ionic Migration under Bias in $\mathrm{CH}_{3} \mathrm{NH}_{3} \mathrm{Pbl}_{3-\mathrm{x}} \mathrm{C}_{1 x}$-Based Perovskite Solar Cells Using GD-OES Analysis, ACS Energy Letters 2017, 2, 943-949.

13. Unger, E. L.; Hoke, E. T.; Bailie, C. D.; Nguyen, W. H.; Bowring, A. R.; Heumuller, T.; Christoforo, M. G.; McGehee, M. D. Hysteresis and transient behavior in current-voltage measurements of hybridperovskite absorber solar cells, Energy \& Environmental Science 2014, 7, 3690-3698.

14. van Reenen, S.; Kemerink, M.; Snaith, H. J. Modeling Anomalous Hysteresis in Perovskite Solar Cells, Journal of Physical Chemistry Letters 2015, 6, 3808-3814.

15. Meloni, S.; Moehl, T.; Tress, W.; Franckevicius, M.; Saliba, M.; Lee, Y. H.; Gao, P.; Nazeeruddin, M. K.; Zakeeruddin, S. M.; Rothlisberger, U.; Graetzel, M. Ionic polarization-induced current-voltage hysteresis in $\mathrm{CH}_{3} \mathrm{NH}_{3} \mathrm{PbX}_{3}$ perovskite solar cells, Nature Communications 2016, 7, Article number: 10334.

16. Correa-Baena, J.-P.; Turren-Cruz, S.-H.; Tress, W.; Hagfeldt, A.; Aranda, C.; Shooshtari, L.; Bisquert, J.; Guerrero, A. Changes from Bulk to Surface Recombination Mechanisms between Pristine and Cycled Perovskite Solar Cells, ACS Energy Letters 2017, 2, 681-688.

17. Tress, W.; Marinova, N.; Moehl, T.; Zakeeruddin, S. M.; Nazeeruddin, M. K.; Grätzel, M. Understanding the Rate-Dependent J-V hysteresis, Slow Time Component, and Aging in $\mathrm{CH}_{3} \mathrm{NH}_{3} \mathrm{Pbl}_{3}$ Perovskite Solar Cells: The Role of a Compensated Electric Field, Energy \& Environmental Science 2015, 8, 995-1004.

18. Calado, P.; Telford, A. M.; Bryant, D.; Li, X.; Nelson, J.; O’Regan, B. C.; Barnes, P. R. F. Evidence for ion migration in hybrid perovskite solar cells with minimal hysteresis, Nature Communications 2016, 7, 13831.

19. Li, C.; Guerrero, A.; Zhong, Y.; Graser, A.; Luna, C. A. M.; Kohler, J.; Bisquert, J.; Hildner, R.; Huettner, S. Real-Time Observation of lodide Ion Migration in Methylammonium Lead Halide Perovskites, Small 2017, 13, Article No: UNSP 1701711.

20. Li, W.; Rothmann, M. U.; Liu, A.; Wang, Z. Y.; Zhang, Y. P.; Pascoe, A. R.; Lu, J. F.; Jiang, L. C.; Chen, Y.; Huang, F. Z.; Peng, Y.; Bao, Q. L.; Etheridge, J.; Bach, U.; Cheng, Y. B. Phase Segregation Enhanced Ion Movement in Efficient Inorganic CsPbIBr2 Solar Cells, Advanced Energy Materials 2017, 7, Article Number: 1700946.

21. Vashishtha, P.; Halpert, J. E. Field-Driven Ion Migration and Color Instability in Red-Emitting Mixed Halide Perovskite Nanocrystal Light-Emitting Diodes, Chemistry of Materials 2017, 29, 5965-5973.

22. Tang, X.; van den Berg, M.; Gu, E.; Horneber, A.; Matt, G. J.; Osvet, A.; Meixner, A. J.; Zhang, D.; Brabec, C. J. Local Observation of Phase Segregation in Mixed-Halide Perovskite, Nano Letters 2018, 18, 2172-2178.

23. Peng, W.; Aranda, C.; Bakr, O. M.; Garcia-Belmonte, G.; Bisquert, J.; Guerrero, A. Quantification of Ionic Diffusion in Lead Halide Perovskite Single Crystals, ACS Energy Letters 2018, 3, 1477-1481. 
24. Motti, S. G.; Meggiolaro, D.; Barker, A. J.; Mosconi, E.; Perini, C. A. R.; Ball, J. M.; Gandini, M.; Kim, M.; Angelis, F. D.; Petrozza, A. Controlling Competing Photochemical Reactions stabilizes perovskite solar cells Nature Photonics, 2019, 13, doi: 10.1038/s41566-019-0435-1.

Stabilizes Perovskite Solar Cells, Nature Photonics 2019, 13, doi: 10.1038/s41566-019-0435-1.

25. Ghosh, S.; Pal, S. K.; Karki, K. J.; Pullerits, T. Ion Migration Heals Trapping Centers in $\mathrm{CH}_{3} \mathrm{NH}_{3} \mathrm{PbBr}_{3}$ Perovskite, ACS Energy Letters 2017, 2, 2133-2139.

26. Kim, G. Y.; Senocrate, A.; Yang, T.-Y.; Gregori, G.; Grätzel, M.; Maier, J. Large tunable photoeffect on ion conduction in halide perovskites and implications for photodecomposition, Nature Materials 2018, $17,445-449$.

27. Li, J.; Dong, Q.; Li, N.; Wang, L. Direct Evidence of Ion Diffusion for the Silver-Electrode-Induced Thermal Degradation of Inverted Perovskite Solar Cells, Advanced Energy Materials 2017, 7, 1602922.

28. Hoke, E. T.; Slotcavage, D. J.; Dohner, E. R.; Bowring, A. R.; Karunadasa, H. I.; McGehee, M. D. Reversible Photoinduced Trap Formation in Mixed-Halide Hybrid Perovskites for Photovoltaics, Chemical Science 2015, 6, 613-617.

29. Yoon, S. J.; Draguta, S.; Manser, J. S.; Sharia, O.; Schneider, W. F.; Kuno, M.; Kamat, P. V. Tracking lodide and Bromide lon Segregation in Mixed Halide Lead Perovskites during Photoirradiation, ACS Energy Letters 2016, 1, 290-296.

30. Yoon, S. J.; Kuno, M.; Kamat, P. V. Shift Happens. How Halide lon Defects Influence Photoinduced Segregation in Mixed Halide Perovskites, ACS Energy Letters 2017, 2, 1507-1514.

31. Barker, A. J.; Sadhanala, A.; Deschler, F.; Gandini, M.; Senanayak, S. P.; Pearce, P. M.; Mosconi, E.; Pearson, A.; Wu, Y.; Srimath Kandada, A. R.; Leitjens, T.; De Angelis, F.; Dutton, S. E.; Petrozza, A.; Friend, R. H. Defect-Assisted Photoinduced Halide Segregation in Mixed-Halide Perovskite Thin Films, ACS Energy Letters 2017, 2, 1416-1424.

32. Rosales, B. A.; Men, L.; Cady, S. D.; Hanrahan, M. P.; Rossini, A. J.; Vela, J. Persistent Dopants and Phase Segregation in Organolead Mixed-Halide Perovskites, Chemistry of Materials 2016, 28, 6848-6859.

33. Samu, G. F.; Janáky, C.; Kamat, P. V. A Victim of Halide lon Segregation. How Light Soaking Affects Solar Cell Performance of Mixed Halide Lead Perovskites, ACS Energy Letters 2017, 2, 1860-1861.

34. Yun, J. S.; Seidel, J.; Kim, J.; Soufiani, A. M.; Huang, S.; Lau, J.; Jeon, N. J.; Seok, S. I.; Green, M. A.; Ho-Baillie, A. Critical Role of Grain Boundaries for Ion Migration in Formamidinium and Methylammonium Lead Halide Perovskite Solar Cells, Advanced Energy Materials 2016, 6, 1600330.

35. Gualdrón-Reyes, A. F.; Yoon, S. J.; Mora-Seró, I. Recent insights for achieving mixed halide perovskites without halide segregation, Current Opinion in Electrochemistry 2018, 11, 84-90.

36. Draguta, S.; Sharia, O.; Yoon, S. J.; Brennan, M. C.; Morozov, Y. V.; Manser, J. M.; Kamat, P. V.; Schneider, W. F.; Kuno, M. Rationalizing the Light-Induced Phase Separation of Mixed Halide OrganicInorganic Perovskites, Nature Communications 2018, 8, Article No. 200 (DOI: 10.1038/s41467-017-002842).

37. Bischak, C. G.; Hetherington, C. L.; Wu, H.; Aloni, S.; Ogletree, D. F.; Limmer, D. T.; Ginsberg, N. S. Origin of Reversible Photoinduced Phase Separation in Hybrid Perovskites, Nano Letters 2017, 17, 10281033.

38. Slotcavage, D. J.; Karunadasa, H. I.; McGehee, M. D. Light-Induced Phase Segregation in HalidePerovskite Absorbers, ACS Energy Letters 2016, 1, 1199-1205.

39. Azpiroz, J. M.; Mosconi, E.; Bisquert, J.; De Angelis, F. Defect migration in methylammonium lead iodide and its role in perovskite solar cell operation, Energy \& Environmental Science 2015, 8, 2118-2127. 40. Akkerman, Q. A.; D'Innocenzo, V.; Accornero, S.; Scarpellini, A.; Petrozza, A.; Prato, M.; Manna, L. Tuning the Optical Properties of Cesium Lead Halide Perovskite Nanocrystals by Anion Exchange Reactions, Journal of the American Chemical Society 2015, 137, 10276-10281. 
41. Pellet, N.; Teuscher, J.; Maier, J.; Grätzel, M. Transforming Hybrid Organic Inorganic Perovskites by Rapid Halide Exchange, Chemistry of Materials 2015, 27, 2181-2188.

42. Jang, D. M.; Park, K.; Kim, D. H.; Park, J.; Shojaei, F.; Kang, H. S.; Ahn, J.-P.; Lee, J. W.; Song, J. K. Reversible Halide Exchange Reaction of Organometal Trihalide Perovskite Colloidal Nanocrystals for FullRange Band Gap Tuning, Nano Letters 2015, 15, 5191-5199.

43. Scheidt, R. A.; Atwell, C.; Kamat, P. V. Tracking Transformative Transitions: From CsPbBr3 Nanocrystals to Bulk Perovskite Films, ACS Materials Letters 2019, 1, 8-13.

44. Eames, C.; Frost, J. M.; Barnes, P. R. F.; O’Regan, B. C.; Walsh, A.; Islam, M. S. Ionic transport in hybrid lead iodide perovskite solar cells, Nature Communications 2015, 6, 7497.

45. Brennan, M. C.; Draguta, S.; Kamat, P. V.; Kuno, M. Light-Induced Anion Phase Segregation in Mixed Halide Perovskites, ACS Energy Letters 2018, 3, 204-213.

46. Li, C.; Guerrero, A.; Huettner, S.; Bisquert, J. Unravelling the role of vacancies in lead halide perovskite through electrical switching of photoluminescence, Nature Communications 2018, 9, 5113.

47. Walsh, A.; Stranks, S. D. Taking Control of Ion Transport in Halide Perovskite Solar Cells, ACS Energy Letters 2018, 3, 1983-1990.

48. Padchasri, J.; Yimnirun, R. Effects of Annealing Temperature on Stability of Methylammonium Lead lodide Perovskite Powders, Journal of Alloys and Compounds 2017, 720, 63-69.

49. Li, Y.; Xu, X.; Wang, C.; Ecker, B.; Yang, J.; Huang, J.; Gao, Y. Light-Induced Degradation of $\mathrm{CH}_{3} \mathrm{NH}_{3} \mathrm{Pbl}_{3}$ Hybrid Perovskite Thin Film, The Journal of Physical Chemistry C 2017, 121, 3904-3910.

50. Samu, G. F.; Scheidt, R. A.; Kamat, P. V.; Janáky, C. Electrochemistry and Spectroelectrochemistry of Lead Halide Perovskite Films: Materials Science Aspects and Boundary Conditions, Chemistry of Materials 2018, 30, 561-569.

51. Manser, J. S.; Kamat, P. V. Band Filling with Charge Carriers in Organometal Halide Perovskites, Nature Photonics 2014, 8, 737-743.

52. Stamplecoskie, K. G.; Manser, J. S.; Kamat, P. V. Dual Nature of the Excited State in OrganicInorganic Lead Halide Perovskites, Energy \& Environmental Science 2015, 8, 208 - 215.

53. Draguta, S.; Thakur, S.; Morozov, Y. V.; Wang, Y.; Manser, J. S.; Kamat, P. V.; Kuno, M. Spatially Non-uniform Trap State Densities in Solution-Processed Hybrid Perovskite Thin Films, The Journal of Physical Chemistry Letters 2016, 715-721.

54. Herz, L. M. Charge-Carrier Mobilities in Metal Halide Perovskites: Fundamental Mechanisms and Limits, ACS Energy Letters 2017, 1539-1548.

55. Stranks, S. D. Nonradiative Losses in Metal Halide Perovskites, ACS Energy Letters 2017, 15151525.

56. Yoon, S. J.; Stamplecoskie, K. G.; Kamat, P. V. How Lead Halide Complex Chemistry Dictates the Composition of Mixed Halide Perovskites, The Journal of Physical Chemistry Letters 2016, 7, 1368-1373.

57. Wieghold, S.; Tresback, J.; Correa-Baena, J.-P.; Hartono, N. T. P.; Sun, S.; Liu, Z.; Layurova, M.; VanOrman, Z. A.; Bieber, A. S.; Thapa, J.; Lai, B.; Cai, Z.; Nienhaus, L.; Buonassisi, T. Halide heterogeneity affects local charge carrier dynamics in mixed-ion lead perovskite thin films, Chemistry of Materials 2019 31, 3712-3721.

58. Ravi, V. K.; Scheidt, R. A.; Nag, A.; Kuno, M.; Kamat, P. V. To Exchange or Not to Exchange. Suppressing Anion Exchange in Cesium Lead Halide Perovskites with $\mathrm{PbSO}_{4}$-Oleate Capping, ACS Energy Letters 2018, 3, 1049-1055.

59. Hoffman, J. B.; Schleper, A. L.; Kamat, P. V. Transformation of Sintered $\mathrm{CsPbBr}_{3}$ Nanocrystals to Cubic $\mathrm{CsPbl}_{3}$ and Gradient $\mathrm{CsPbBr}_{x} \mathrm{I}_{3-\mathrm{x}}$ through Halide Exchange, Journal of the American Chemical Society 2016, 138, 8603-8611.

60. Eames, C.; Frost, J. M.; Barnes, P. R. F.; O'Regan, B. C.; Walsh, A.; Islam, M. S. Ionic Transport in Hybrid Lead lodide Perovskite Solar Cells, Nat Commun 2015, 6, Article No. 8497 
61. Domanski, K.; Roose, B.; Matsui, T.; Saliba, M.; Turren-Cruz, S. H.; Correa-Baena, J. P.; Carmona, C. R.; Richardson, G.; Foster, J. M.; De Angelis, F.; Ball, J. M.; Petrozza, A.; Mine, N.; Nazeeruddin, M. K.; Tress, W.; Gratzel, M.; Steiner, U.; Hagfeldt, A.; Abate, A. Migration of Cations Induces Reversible Performance Losses Over Day/Night Cycling lin Perovskite Solar Cells, Energy \& Environmental Science 2017, 10, 604-613.

62. Ruth, A.; Brennan, M. C.; Draguta, S.; Morozov, Y. V.; Zhukovskyi, M.; Janko, B.; Zapol, P.; Kuno, M. Vacancy-Mediated Anion Photosegregation Kinetics in Mixed Halide Hybrid Perovskites: Coupled Kinetic Monte Carlo and Optical Measurements, ACS Energy Letters 2018, 3, 2321-2328.

63. Ravi, V. K.; Scheidt, R. A.; DuBose, J.; Kamat, P. V. Hierarchical Arrays of Cesium Lead Halide Perovskite Nanocrystals through Electrophoretic Deposition, Journal of the American Chemical Society 2018, 140, 8887-8894.

64. Xiao, Z.; Zhao, L.; Tran, N. L.; Lin, Y. L.; Silver, S. H.; Kerner, R. A.; Yao, N.; Kahn, A.; Scholes, G. D.; Rand, B. P. Mixed-Halide Perovskites with Stabilized Bandgaps, Nano Letters 2017, 17, 6863-6869. 